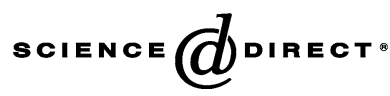

The Leadership Quarterly 16 (2005) 625-653
The

Leadership

Quarterly

\title{
Spirituality and leadership: An empirical review of definitions, distinctions, and embedded assumptions
}

\author{
Eric B. Dent ${ }^{\mathrm{a}, *}$, M. Eileen Higgins ${ }^{\mathrm{b}}$, Deborah M. Wharff ${ }^{\mathrm{a}}$ \\ ${ }^{\text {a } U n i v e r s i t y ~ o f ~ N o r t h ~ C a r o l i n a, ~ P e m b r o k e, ~ U n i t e d ~ S t a t e s ~}$ \\ ${ }^{\mathrm{b}}$ Frostburg State University, United States
}

\begin{abstract}
Spirituality and its relationship to workplace leadership is a compelling issue for management practitioners and researchers. The field of study is still in its infancy and as such is marked by differences in definitions and other basic characteristics. Much of what has been written on this subject has appeared in general, rather than academic publications and consequently may lack rigor. The purpose of this study is to analyze known academic articles for how they characterize workplace spirituality, explore the nexus between spirituality and leadership, and discover essential factors and conditions for promoting a theory of spiritual leadership within the context of the workplace. An emergent process was used to identify and validate eight areas of difference and/or distinction in the workplace spirituality literature: 1.) definition, 2.) connected to religion, 3.) marked by epiphany, 4.) teachable, 5.) individual development, 6.) measurable, 7.) profitable/productive, and 8.) nature of the phenomenon. Eighty-seven scholarly articles were coded for each of these areas. Findings conclude that most researchers couple spirituality and religion and that most either have found, or hypothesize a correlation between spirituality and productivity. The emergent categories offer provocative new avenues for the development of leadership theory.
\end{abstract}

(C) 2005 Elsevier Inc. All rights reserved.

Keywords: Spirituality; Leadership; Organizations; Definition; Religion; Assumptions

\section{Introduction}

The notion of spirituality in the workplace has attracted a considerable amount of attention in the last decade. The popular literature on this subject has also flourished (Gibbons, 2000). Many best-selling

\footnotetext{
* Corresponding author.

E-mail address: eric.dent@uncp.edu (E.B. Dent).
} 
books on leadership and management have "spirit" or a comparable word in the title; the topic of workplace spirituality is beginning to appear in organizational behavior textbooks (Robbins, 2003a,b) indicating that it is now being taught in a mainstream manner in both graduate and undergraduate business programs; and many conferences on this subject are now scheduled around the world (Biberman \& Altman, 2004).

Within the past decade, the concept of spirituality and religion in the workplace has gained enough strength and interest that the Academy of Management has created a new special interest group for its membership. This group, Management, Spirituality, and Religion, has grown to more than 500 members since its inception (Robbins, 2003a) and is helping to legitimize within academia the study of spirituality in the workplace while simultaneously paving the way for introducing this emerging concept into the leadership research agenda (Academy of Management, 2004). Yet, the field of study is marked by all of the typical characteristics of paradigm development including a lack of consensus about a definition of workplace spirituality and a lack of clarity about boundaries of the subject in context of leadership. For example, some writers include ethics or team spirit within the boundaries although others do not, and some claim a nexus between spirituality and leadership practices while others treat workplace spirituality as an individual phenomenon.

Goertzen \& Barbuto (2001) in their empirical review of the literature on individual spirituality contend that spirituality is addressed through several paradigms: self-actualization and spirituality, purpose and meaning in life and spirituality, health and wellness as outcomes of spirituality, spirituality in the workplace, and spirituality and leadership. It is the last two treatments that are the focus of this paper, specifically dimensions of spirituality in the workplace that appear most frequently in the literature and portend to have a significant contribution to the further development of leadership theory.

The pace of theory development of leadership has progressed slowly (Yukl, 2002), yet over the last two decades significant advances have been made in integrating the theories of leadership and human development (Cook-Greuter, 2002; Wilber, 2000a). While empirical research on leadership remains narrowly focused on leadership behaviors, power dimensions, traits and skills, and situational contexts, promising new areas of research have emerged that recognize leadership as the manifestation of a leader's spiritual core (Fairholm, 1998), leadership as a collective phenomenon (Drath \& Palus, 1994), and leadership as concerned with an individual's thinking, inquiring, perceiving, valuing, and acting in a community rather than an individual context (Eggert, 1998, p. 223).

These lines of research suggest the spiritual domain as an integral component of leadership and put forth spirituality as one variable of an integrated leadership development model (Cook-Greuter, 2002; Sanders, Hopkins, \& Geroy, 2003; Thompson, 2000; Wilber, 2000a). The premise of this integrated model is that as development occurs there is a transcending of worldviews and a shift to higher levels of internal locus of control (Sanders et al., 2003), and human growth is achieved through the interplay of individual, community, and environment. At the higher stages of development, leaders are deepening their intuition and inner knowing through a shared consciousness with a higher power or transcendent (Cook-Greuter, 2002; Wilber, 2000a).

The theory development of workplace spirituality and its relationship to leadership is in its infancy. Reichers \& Schneider (1990) call this emerging stage of construct development introduction and elaboration. This first stage is characterized by (a) attempts to legitimatize the new construct, (b) a cascade of articles that attempt to bestow legitimacy on both the research and researchers, and (c) the keen attention of scholars trying to define the new term. The second and third stages (evaluation and 
argument, and consolidation and accommodation), as explained by Reichers and Schneider, consist of first, debates and critiques around the research and findings, and second, the waning of controversies about the topic and the general acceptance and standardization of one or two definitions.

Typical to the first stage is the developmental history of the constructs of spirituality in the workplace and spiritual leadership. That is, in the first stage, there is scant empirical research, and critics point to this dearth as evidence of lack of legitimacy. Hunt (1999), using the Reichers \& Schneider's (1990) framework for Culture and Climate, traces the evolution of leadership over time. He notes that when an emerging construct such as charismatic/transformational leadership is introduced into the leadership field, which had matured to the third stage, the field is thrown back into the first stage to undergo a new search for a common definition and to develop legitimacy of the construct through rigorous empirical research.

Many authors and scholars link spirituality to organizational leadership (Fairholm, 1998; Fry, 2003; Strack, Fottler, Wheatley, \& Sodomka, 2002) as well as other organizational factors such as absenteeism, productivity, turnover, ethicality, stress, and health (Giacalone \& Jurkiewicz, 2003). Giacalone \& Jurkiewicz (2003) state that workplace spirituality can be either active or passive and that these supposedly contradictory elements must be blended together in order to define it. Their definition, which follows, attempts to integrate these conditions: "Workplace spirituality is a framework of organizational values evidenced in the culture that promotes employees' experience of transcendence through the work process, facilitating their sense of being connected to others in a way that provides feelings of completeness and joy" (p. 13). While this definition is only one of many that has appeared in the scholarly literature on the subject, we believe it is broad and explicit enough to serve as a starting point for developing theory.

Spirituality is believed to enhance organizational learning (Bierly, Kessler, \& Christensen, 2000), unify and build communities (Cavanaugh, Hanson, Hanson, \& Hinojoso, 2001), serve the need for connecting to others at work, and to work itself (Khanna \& Srinivas, 2000), and is the source of a healing and harmonizing expression of compassion, wisdom, and connectedness that transcends all egocentric, sociocentric, or anthropocentric forms (Maxwell, 2003). Cacioppe (2000a) argues that leaders have a central role in the evolution of integrating spirituality at work and instilling a sense of the spiritual realm at the individual, team, and organizational level.

Leaders who bring their spirituality to work transform organizations from merely mission-driven activities into places where individual and collective spirituality are encouraged and spiritual development is integrated into the day-to-day work life (Konz \& Ryan, 1999). Such leaders inspire and energize behavior in employees based on meaning and purpose rather than rewards and security, thus compelling employees to transcend their self-interests for the welfare of their organizational members, the sake of the mission (Dehler \& Welsh, 1994, p. 20), and for the good of humanity and the natural world (Maxwell, 2003). Furthermore, Harvey (2001), basing his conclusions on many meetings with chief executive officers (CEOs) and other high ranking executives, notes that many decisions at the highest levels of all kinds of organizations are made on the basis of prayer and that leaders of significant stature and influence care deeply about the spiritual side of their leadership roles and are "starved for opportunities to discuss it" (p. 378).

We also discovered many similarities between workplace spirituality theory and leadership theory. These links and theoretical connections are discussed throughout the article and are further examined for their relationship to leadership theory in the Spiritual Leadership Theory Development section. While scholars clearly identify spirituality as a central thesis of a new paradigm in organizational and 
leadership theory, the ontology of spirituality in the workplace closely resembles the literature on leadership in that there are many dynamic dimensions or contexts for describing and measuring the phenomenon. Sometimes these dimensions confound one another; for example, spirituality as an attribute, which remains relatively static over time versus the manifestation of spirituality, which can be dynamic and change depending on the situation.

Fairholm $(1996,1998)$ was one of the first scholars to put the terms spiritual and leadership together to explain spirituality in context of workplace leadership, and since then others have attempted to validate his model in order to move the field toward a theory of spiritual leadership (e.g., Fairholm, 2002; Fry, 2003). Other authors have put forth spiritual leadership models that relate to constructs such as emotional intelligence, ethics, values, and to leadership models such as charismatic, stewardship, transformational, and servant (Biberman, Whitty, \& Robbins, 1999; Cacioppe, 2000a; Tischler, Biberman, \& McKeage, 2002). To date, these constructs have been confounded and need conceptual distinction (Fry, 2003).

Strack et al. (2002) contend that the research agenda linking spirituality and leadership is a conceptual quagmire because each construct can be defined in hundreds of ways. Our empirical review of scholarship found this to be true, as well. Therefore, the authors of this article conducted a meta analysis of the literature applying the tenets of qualitative narrative analysis (Denzin \& Lincoln, 2000; Miles \& Huberman, 1984) to narrow the scope and to discern whether definitions and other assumptions about workplace spirituality converged around common themes or categories, which could then advance the theory of workplace spirituality and leadership.

It is interesting to note that blind reviews of this article mirror the variation in discussion about the topic of spirituality at the 2004 Academy of Management Conference. Some in the field push for rapid closure on a common definition of spirituality at work, seeing this as a necessary prelude to development of spirituality and its relationship to the theory of leadership. Others see the field of inquiry as the continual pursuit of a richer and richer definition and see no need for an early consensus (Lund Dean, 2001). After searching the academic literature to discover a modicum of agreement regarding definitions and finding none, our sympathies lie more with the latter group. Nevertheless, we remain proponents of conceptual clarity, boundary definition (even if the boundaries are overlapping and/or permeable), and mappings of interrelatedness (which may include mutual causality) (Dent, 2003; Fry \& Smith, 1987). One objective of this article is to make explicit what major concepts need to be considered in a mapping of interrelatedness and what themes are most commonly appearing in definitions and characterizations of workplace spirituality, particularly those that relate to leadership theory.

The primary purpose of this research is to discover essential factors and conditions for promoting a theory of spiritual leadership within the context of the workplace (Whetten, 1989). This study analyzes the scholarly literature and ascertains how researchers characterize the relationship between spirituality and organizational dynamics such as leadership, measurement, and productivity or profit. Using qualitative narrative analysis to surface emergent categories, we make explicit the major concepts of difference in which theory development is still necessary. We analyze the definition of workplace spirituality in every academic article that offered one and present coding results in seven other categories of difference. Interrater agreement and reliability measures are offered for coding of these seven categories. Then, the range of difference is summarized for each. The article concludes with discussions of the implications of this work for spiritual leadership theory development. 


\section{Methodology}

We conducted a qualitative narrative analysis (Miles \& Huberman, 1984) to produce emergent categories rather than predetermined ones. Early in the process two authors each read ten randomly selected scholarly articles (Barley, Meyer, \& Gash, 1988) on spirituality and leadership in organizations. From these twenty articles we identified a number of either explicit or implicit assumptions/claims made by the authors of these articles that were not consistently shared among scholars in this field, yet were central to the work of the author(s). This step resulted in the emergence (Boyatzis, 1998) of eight thematic categories distilled from 25, where important differences and/or distinctions arise in how the subject of workplace spirituality is treated by the authors. Among the original 25 themes, there were many areas of agreement or assumptions about organizational spirituality.

Authors defined spirituality as transformational, moral, and ethical and claim that spirituality assumes integrity, honesty, goodness, knowing, wholeness, congruency, interconnectedness, teamwork, etc. These themes were so pervasive that the more interesting work seemed to be in unearthing areas of differences and/or distinction. Among the original list of 25 themes were emergent topics that were somewhat specific, (environmental spirituality, Eastern religions, spirit vs. soul, right livelihood) or unusual and unique (magic, mystery, whimsy, energy, emptiness, intangibility) so that they were not prevalent enough to code. Future researchers may choose to explore those topics in greater depth.

Thematic categories surfaced from the data as the researchers used an inductive process often called "open coding" (Strauss \& Corbin, 1998) to immerse themselves in the data, discuss and debate among themselves, and be open for patterns and themes to come in to view. Category creation is vital because "categories are the cornerstones of developing theory in that they produce the means by which the theory can be integrated" (Strauss \& Corbin, 1998, p. 7). Solid theory can develop through the interplay of concepts, categories, and propositions in an iterative dance.

A critical aspect to the process was to avoid reading articles simply for content and evidence for a prior theory. The intent was to tease out underlying propositions that make the authors' assertions sensible and valid, while at the same time attempting to identify categories linked to the evolving research question. The decision factors for including the categories were based on the authors' persuasiveness, plausibility, coherence, and pragmatic applicability to theory development (Huberman \& Miles, 2002). The resultant categories hold the most promise for advancing and/or developing theory in the areas of workplace spirituality and leadership.

Twenty randomly-selected articles are more than enough for categories to emerge since Krippendorff (1980) finds that increasing the random sample size beyond twelve articles per coder does not yield changes in the categories. These eight categories and their definitions appear in Table 1. Each category is treated as a two dimensional concept; some dimensions are dichotomous (such as "teachable" - it either is or is not) although others could be either/or (for example, the "nature of phenomenon" - which could be individual or collective), so in the latter case we allowed for coding in either dimension.

\subsection{Literature research and review}

The next task was to identify an appropriate universe of articles on workplace spirituality. Searching Academic Universe/Lexis Nexis, Business section, the first time "spirituality" appears in the title of an 
Table 1

Categories of difference and distinction and coding definitions

1. Definition of workplace spirituality

No pre-determined categorization or dimensions. Definitions are listed and analyzed from each paper that offered one.

For each item below, the statement is prefaced with "The author(s) of the article..." Each category also has an option (c), is silent on the subject (explicitly and implicitly).

2. Religious

(a) Specifically ties the definition of spirituality with religious practice- "religious" meaning, the formal, organized, collective practice of one or more of the major religions of the world.

(b) Makes a distinction between spirituality and religion.

3. Epiphany

(a) Defines spiritual development as arising through a series of discontinuous awakening experiences.

(b) Defines spiritual development as a process that may be continuous and is not dependent on epiphanies (although they may be part of the process of spiritual development).

4. Teachable

(a) Sees someone's spiritual development as impacted by external influences such as formal courses on the concepts and principles of "spirituality" or listening to speakers/teachers on the subject.

(b) Sees someone's spiritual development occurring only or primarily through individual or solitary actions: meditating, being in nature, reading spiritual and/or religious writings, etc.

5. Individual development

(a) Ties spiritual development to a predetermined set of stages of individual development common to all people.

(b) Does not equate spirituality with human development.

6. Measurable

(a) Sees the concept of spirituality as measurable, typically through a survey instrument.

(b) Describes the concept of spirituality as ineffable or ephemeral when attempts to measure occur.

7. Productive/profitable

(a) Offers claims/evidence that spirituality is correlated with organizational performance.

(b) Asserts that spirituality will not impact organizational performance.

8. Nature of the phenomenon

(a) Sees spirituality as strictly an individual concept.

(b) Considers that spirituality may include a collective component. For example, similar to Jung's theoretical collective unconscious, there is a collective spirituality available to all people who choose and equip themselves to experience it.

article is 1990. Neal \& Biberman (2003) identify the sudden increase in spirituality in the workplace as beginning in 1992. Ashmos \& Duchon (2000) and others (Brandt, 1996; Conger, 1994) speculated on corporate America's interest in workplace spirituality and believe it may be best understood by tracing some of the societal trends over the past decade. For instance, many believe that the American workplace has been turned into a tense environment with demoralized workers due to downsizing, reengineering, restructuring, outsourcing, and layoffs, as well as a growing inequity in wages. Also, the workplace has become for many a substitute for extended families, churches, neighborhoods, and civic groups that previously had been the source for the essential human feelings of connectedness and contribution. Since people are spending so much time at work, they want to be able to acknowledge their spiritual center in that environment as well as at home.

Additionally, there has been a growing interest in and curiosity about Eastern philosophies and Pacific Rim cultures (Brandt, 1996, as cited in Ashmos \& Duchon, 2000). Such philosophies and cultures encourage meditation, loyalty to one's groups, and bringing a thoughtful and spiritual perspective to every activity (Ashmos \& Duchon, 2000). Finally, as baby boomers move closer to the ends of their careers, they may become more involved in contemplating the meaning of their lives (Brandt, 1996; 
Conger, 1994, as cited in Ashmos \& Duchon, 2000). Leaders such as Lawrence Pearlman, then CEO of Ceridian Corporation of Minneapolis and a proponent of workplace spirituality, recognized that employee creativity needs a fuller expression at work and that such expression is difficult when work itself is not meaningful (Ashmos \& Duchon, 2000).

We specified that the universe for our research and study should consist of all scholarly articles on workplace spirituality in English that have appeared since 1990 (not excluding earlier works that would surface through our cascading process, described below). Identification of the articles was an iterative process. We searched ABI Inform, Business Source Premier, Emerald, Wilson Select, Expanded Academic Index ASAP, Prompt (Expanded Academic ASAP), Academic Search Premier, and Academic Universe/Lexis Nexis using spirituality, spiritual, leadership, management, work, and organizations and any combinations of these as keywords. We did not search on "religion" because we did not want articles that did not also have one of the other key words listed.

Each abstract was reviewed to ensure that the keywords were appropriate proxies for the subject of interest. We added to the list any articles on workplace spirituality known to the researchers but not identified by the search. This step was important because many articles on spirituality are published in journals that are not yet indexed by the major database services. We obtained copies of all of these papers and inspected their reference lists for additional articles. We also showed our list to several wellknown scholars in the field to see whether they were aware of articles we were missing to ensure that our sample was as exhaustive as possible. The final sample, culled from 103 possible articles, consisted of 87 scholarly articles published in 31 different outlets. The following four journals published the most articles on workplace spirituality, including, in some cases, dedicated special issues: Journal of Management Inquiry; Journal of Managerial Psychology; Journal of Organizational Change Management; Leadership and Organization Development Journal.

\subsection{Results of the coding}

All three authors participated in the coding and each article was coded by two of the authors. It was not difficult to achieve agreement about topics such as whether the article author defined workplace spirituality in a way that tied it to religion, so high levels of interrater agreement and reliability were achieved. Cohen's Kappa was used to calculate the interrater agreement (Fleiss, 1981; Shrout \& Fleiss, 1979). Fleiss (1981) considers Kappa levels above 0.75 as excellent. Five of the seven dimensions had Kappa's in the "excellent" range. The two that are in the "acceptable" range are individual development and nature of the phenomenon. (The agreement on this dimension is actually higher than Kappa reflects. Kappa is designed to measure agreement on domains with discrete units. Since the "both" coding is not discrete from "individual" and "collective," there is some agreement when one coder, for example, indicates "individual" and the other indicates "both" although Kappa reflects that as a total mismatch.) All statistics were highly significant. Cronbach's Alpha was used to assess interrater reliability. Each dimension had a reliability metric of at least 0.78 , suggesting high levels of reliability. The results of the coding are in Table 2. These data provide a snapshot of what "is" with respect to the scholarly work produced.

These eight categories form the basis of the analysis of the scholarly literature on workplace spirituality and provide a focus for exploring and theorizing the notion of workplace spirituality in terms of leadership theory. We are not suggesting that the eight categories comprehensively comprise the characteristics of workplace spirituality and spiritual leadership; rather these categories emerged as the 
Table 2

Interrater agreement and reliability by category and dimension

\begin{tabular}{lccclll}
\hline Category & Yes & No & Both & No mention & Cohen's kappa & Cronbach's alpha \\
\hline Tied to religion & 25 & 15 & 18 & 29 & $0.78^{*}$ & $0.82^{*}$ \\
Epiphany & 9 & 15 & 2 & 61 & $0.82^{*}$ & 0.91 \\
Teachable & 26 & 3 & 1 & 57 & $0.72^{*}$ & 0.88 \\
Individual development & 44 & 2 & 0 & 41 & $0.87^{*}$ & 0.81 \\
Measurable & 25 & 7 & 0 & 55 & $0.82^{*}$ & 0.91 \\
Productive/profitable & 48 & 1 & 0 & 38 & $0.69^{*}$ & 0.92 \\
Nature of the phenomenon & 17 & 9 & 42 & 19 & 0.78
\end{tabular}

For "definition of workplace spirituality" no categorization was predetermined. For "nature (of the phenomenon)" the "no" column indicates the "collective" assumption.

Consequently, each definition offered was analyzed rather than coded.

$* p<.00001$.

prominent factors in the scholarship to date. The following review of the literature and discussion of findings are arrayed in terms of these eight areas.

\section{Discussion of emergent categories-distinctions}

\subsection{Definitions of workplace spirituality}

Mohamed, Hassan, \& Wisnieski (2001) claim there are more definitions of spirituality than there are authors/researchers to write about it. The present researchers also found this to be true and consequently, for space considerations, provide only a moderate sampling of the variety of definitions discovered during their research and coding. Howard (2002) observes that spirituality is so difficult to describe because it is highly individual and intensely personal, as well as inclusive and universal. The definitions offered cover a wide range of phenomena including:

(a) Khanna \& Srinivas (2000), who call it "beauty" and then discuss transformational relationships;

(b) Levine (1994), who, in addition to creativity, insight, openness, and extraordinary performance calls it emptiness-emptying oneself or creating a vessel for receiving or containing spirit;

(c) Boozer (1998), who calls it "everything," as does Sperry (1997), who defines it as a spiritual union with any- and everything;

(d) Levy (2000), who says it's inside of him, his quiet zone, very personal, encompassing everything he does;

(e) Mason \& Welsh (1994) who define it as wonder, play, ignorance, spontaneity, joy, imagination, celebration, discernment, insight, and creativity; and,

(f) Lichtenstein (1997) who writes of grace, magic and a miracle - components of personal and organizational transformation.

In addition, Goertzen \& Barbuto (2001) describe three components of spirituality: 1.) belief in the sacred; 2.) belief in the Unity; and 3.) belief in transformation; Strack et al. (2002) interviewed 20 transformational leaders who defined it as "God" or some other transcendent power, the source of one's 
value and meaning, an awareness of one's inner self, and a way of integrating all aspects of oneself into a whole. Freshman (1999), Konz \& Ryan (1999), Krishnakumar \& Neck (2002) among others, all describe spirituality as being pluralistic. Gibbons' (2000) definition is the search for direction, meaning, inner wholeness and connection to others, to non-human creation, and to a transcendent. The majority defined spirituality as a search for meaning, reflection, inner connectedness, creativity, transformation, sacredness, and energy.

Readers of these articles will quickly observe that the various definitions are sometimes separate, sometimes overlapping, sometimes contradictory, and sometimes quite expansive and personal. Giacalone \& Jurkiewicz's (2003) definition (discussed earlier) attempts to both reconcile and incorporate these contradictions. For example, they note that the passive aspects of workplace spirituality such as beliefs and rituals are primarily internal and remain constant over time, whereas the dynamic aspects such as skills, resources, capabilities, or abilities evolve and develop over time, and interact with the external environment. They note that research tends to focus on one aspect or the other instead of treating the phenomenon like the literature treats power-inclusively-in that it can either be a noun (something one has) or a verb (something one does).

Gibbons (2000) sees the fundamental weakness of the field as the lack of clear definitions and conceptualizations. This definitional dilemma is not unprecedented. For example, Stogdill (1974) noted that "there are almost as many definitions of leadership as there are persons who have attempted to define the concept" (p. 259). Moreover, Schein (1992) claimed that considerable academic debate had occurred around the approaches to define and study culture. He stated that such debate is a healthy sign that testifies to the importance of culture as a concept. He goes on to acknowledge, however, that both scholars and practitioners may become frustrated with fuzzy and inconsistent definitions. The attempts to find a unified definition of workplace spirituality by researchers in the field and the subsequent frustrations involved in doing so echo the experiences of both the leadership and culture researchers. Where conceptual boundaries form will be a critical step for the development of the field of workplace spirituality and the advancement of leadership theory.

\subsection{Religion}

\subsubsection{Tied to religion}

Several of the articles see spirituality in a religious context, and many do not. We begin with several examples of the former. Ali \& Gibbs (1998) relate the Ten Commandments of three major religions (Judaism, Christianity, and Islam) to the work ethics and practices of their believers. They argue that in a global marketplace and economy, with diversity as the norm rather than the exception, leaders and managers can benefit from understanding the basic embedded religious drives that members of these three religions may bring to their work environment. Cash \& Gray (2000) define spirituality, religion, and "sincerely held beliefs" (p. 127) and conclude that to protect the rights of all employees, all three should be regarded as the same.

Elmes \& Smith (2001) contend that workplace empowerment has a strong spiritual underpinning with roots in Puritan and Christian ideals, emphasizing that hard work, right living, and doing for others lead to individual and corporate prosperity. Gibbons (2000) claims that spirituality cannot be separated from ancient religious traditions because it is important to many people: 95\% of Americans believe in God; there are 1.5 billion Buddhists in the world; and Western Europe is estimated to be $80 \%$ Christian. Hicks (2002) critically examines the spirituality-religion dichotomy and argues that the scholars of leadership 
have too broadly defined spirituality and fail to acknowledge the religious diversity, despite the fact that America is one of the most religiously diverse nations in the world (Eck, 2001). He contends that scholars invoke the religion-spirituality dichotomy to argue that if a practice or belief is controversial, it is probably religious and not spiritual, and thus conflict is defined away.

Korac-Kakabadse, Kouzmin, \& Kakabadse (2002) state that spirituality includes terms such as energy, meaning, and knowing, and that it can be related to the various spiritualities of Tao, Buddhism, Hinduism, Zen, and Native American. Kriger \& Hanson (1999) suggest that the world's major religious traditions have endured the test of time and note that the inherent values in those religions may be relevant to the organizations of today. Moch \& Bartunek (submitted for publication) contend that spirituality and religion cannot be separated and illustrate how religion interprets spirituality and how religion and business have coevolved over the last three centuries. Mohamed et al. (2001) argue that there is no significant difference between religion and spirituality despite the fact that many see the prior as negative and the latter as positive.

Pratt (2000) in his ethnographic research found that deeply infusing religious values into the organization-putting God before one's business can help members "make sense" of unexpected events by helping them take an organizational perspective, which includes the embedded religious and/or spiritual component. Religion may also provide a conceptual framework for governance (Duignan \& Bhindi, 1997), which may promote a leadership praxis linking the theory, practices, and ethics of leadership.

\subsubsection{Not tied to religion}

Conversely, several articles contend that spirituality should be seen as separate from any religious context. For example, Ashmos \& Duchon (2000) argue that spirituality is neither about religion nor about getting people to accept a specific belief system. Rather it is about employees who understand themselves as spiritual beings at work whose souls need nourishment, a sense of purpose and meaning, and a sense of connectedness to one another and to their workplace community. Bierly et al. (2000) define spirituality as moral and emotional in nature, which involves an understanding and appreciation of one's position in the universe, one's soul, and the role of a God. Organized religions provide rituals, routines, and ceremonies that can provide a vehicle for achieving spirituality. They contend that one could be religious by faithfully attending the religious rituals but lack spirituality.

Dehler \& Welsh (1994) claim that religion is not required for context in defining spirituality and its relationship to the workplace. Elkins, Hedstrom, Hughes, Leaf, \& Saunders' (1988) research shows that a growing number of people are developing their spirituality outside traditional, organized religion, citing a study by Shafranske \& Malony (1985) that found $74 \%$ of the respondents indicated that organized religion was not the primary source of their spirituality. Goertzen \& Barbuto (2001), in their meta-analysis of literature on spirituality, argue that it is critical to dispel the myth about spirituality, that it is not necessarily a religious state (Brandt, 1996; Maher \& Hunt, 1993; Mitroff \& Denton, 1999). While the Giacalone \& Jurkiewicz (2003) definition includes transcendence and connection, it does not explicitly acknowledge religion as an integral aspect to workplace spirituality.

Most of the articles suggest that spirituality can be defined separately from religion. Those who believe it can, point out that people can participate in activities of a religious institution without having a spiritual experience, and that it is possible to have a spiritual experience outside an environment of religion. It is also the case that for many people, religion often has the negative connotations of being parental, authoritarian, and requiring unconscious obedience (Mohamed et al., 2001). Spirituality for many means self-managed, adult, self-directed, and conscious development. As model and theoretical 
development proceeds, this research suggests that spirituality should be defined in a context that takes religion into consideration.

By religion, though, we are not restricting our comments to a large, institutional religion such as Islam or Catholicism. The various twelve-step programs, for example, represent a codified set of beliefs. Those articles that contend that spirituality can be developed independent of a system of belief (e.g., religion and values) have not taken the time to make explicit the many beliefs implicit in how they define spirituality. The integration of religion and spirituality offers researchers provocative new vistas in developing leadership theory, particularly as it relates to mutual causality (Dent, 2003) of leaders' values, belief systems, and their organizational policies and practices.

\subsection{Epiphany}

Some writers describe spiritual development as arising through a series of discontinuous awakening experiences. Delbecq (1999, 2000), Mitroff \& Denton (1999), Moberg \& Calkins (2001), Neal, Bergmann Lichtenstein, \& Banner (1999) cite CEOs and managers who provided examples of intense moments of suffering or epiphanies as transforming experiences and pivotal aspects of the spiritual journey. Tosey \& Robinson (2002) discuss the personal transformation that must take place in developing spirituality and its relationship to organizational transformations. After studying the contexts in which transformation was used in numerous organizations, they identified four distinct types of change, all referred to as transformations, and created a matrix with four quadrants to describe these distinctions.

From a historical perspective, Moch \& Bartunek (submitted for publication) liken epiphany to "great awakenings" in the coevolution of religion and business and contend that through discontinuous experiences and integration of business and religion, a fourth "great awakening," which puts a priority on creating a spiritual renewal, is occurring.

Other authors describe spiritual development as a process that may be continuous and is not dependent on epiphanies (although they may be part of the process of spiritual development). Several articles suggest that if spiritual development is continuous, leaders could develop or enhance their spirituality through activities such as meditation, reflection, and therapy. Developing spirituality through reflection and reflective thinking was the methodology most frequently mentioned in the research (Bell \& Taylor, 2001; Delbecq, 2000; Duignan \& Bhindi, 1997; Howard, 2002; Khanna \& Srinivas, 2000; Moberg \& Calkins, 2001). In each of these cases, the authors explicitly or implicitly see spiritual development as a continuous process, certainly not a linear progression, but one in which spirituality can develop steadily while recognizing a periodic discontinuity in development.

Whether spiritual development is continuous or discontinuous was predominantly a topic on which articles were silent. Of those that commented or implied a position more articles saw the process as continuous. Giacalone \& Jurkiewicz (2003) claim employees experience transcendence through the work process, therefore implying spiritual development as a continuous process.

There is consensus that the process of spiritual development is analogous to that of personal and moral development (Fowler, 1981; Kegan, 1982). There is also generally consensus that spiritual development includes moments when greater awareness is achieved. These moments also fit into continuous development models that generally have boundary-crossing experiences or times. Intellectually, unless empirical research emerges that spirituality develops in only a manner marked by discontinuities, theoretical development should assume that the phenomenon is continuous (which allows for periodic 
discontinuities). This line of inquiry is consistent with the research advancing the relationship of leadership development with Kohlberg's stages of human and moral development (Kohlberg \& Hersh, 2001) and which applies Wilber's (2000a,b) integral transformation and evolution of consciousness constructs.

\subsection{Teachable}

Some authors see someone's spiritual development as impacted by external influences such as formal courses on the concepts and principles of "spirituality" or listening to speakers/teachers on the subject. Delbecq (2000) provides testimony and evidence that his graduate-level course entitled Spirituality for Business Leadership had a positive impact on the spiritual development of its participants. Other authors suggest methods for integrating spirituality concepts into business management and leadership academic programs (Butts, 1999; Lichtenstein, 1997) and cite schools of business that have offered courses on spiritual topics such as discernment, prayer and meditation, spiritual challenges of wealth versus poverty of spirit, and contemplative practices that include retreats (Cavanaugh, 1999). Pheng (1999) contends that leadership development programs should integrate the basic guiding principles found in the Holy Bible to teach leaders the skills necessary to achieve managerial efficacy.

Korac-Kakabadse \& Korac-Kakabadse (1997) provide an in-depth leadership analysis that examines the manager versus leader question and states that spiritual leaders must reflect on their lives to discover and understand their purposes so that they can lead with authenticity and integrity. They claim that these leaders are developed through education, training and/or experience and commitment. Duignan \& Bhindi (1997) claim morality is acquired through education, that education is values-based and should reflect what society and culture deem to be right.

Other writers see someone's spiritual development occurring only or primarily through individual or solitary actions: meditating, being in nature, reading spiritual and/or religious writings, and so forth. Encouraging reflective thinking and use of retreats for self-renewal were cited as methods for developing spirituality in context of business, ethics, and morals. The Spiritual Exercises developed by St. Ignatius Loyola were identified as tools to engage the emotions and to serve as models for reflection in business settings (Konz \& Ryan, 1999; Moberg \& Calkins, 2001). Freshman (1999) contends that spirituality is a solitary phenomenon and therefore there is no single definition or application of spirituality. For this reason, he suggests that learning about and development of spirituality is a unique experience and therefore participants must create their definitions and goals for learning interventions.

Other research settings provided evidence that contemplative practices, reading scriptures, saying prayers, singing, and participating in religious activities led to increased spirituality (Korac-Kakabadse et al., 2002; Sass, 2000). Burack (1999) cites research that claims the process of achieving spiritual growth is "one and the same" as achieving mental growth (Peck, 1980, p. 11) in that life takes on meaning through the process of meeting and solving problems. It is the challenge of thought patterns and creative problem solving leading to new solutions that result in learning and the experience of spiritual growth.

Overwhelming evidence suggests that workplace spirituality should be considered a phenomenon that is impacted by teaching. Teachers and organizational leaders appear to be able to take actions that affect spirituality. An explanation for those not taking this view can be found in the adult learning literature. In models such as Kolb's (1988) learning style or Vaill's (1996) notion of "learning as a way of being," adults have preferences for learning such as "orientation toward reflective observation" or "experiential 
learning." It could be that those who see spiritual development not impacted by teaching are those who are assuming more reflective modes in their writing. At face, it seems that several learning modes will be operative in spiritual growth and that further theoretical work should not preclude any at this point.

The "teachable" category offers insight into new ways of tailoring leadership development programs for the purpose of spiritual growth. Burns (1978) put forth an argument more than two decades ago that the most marked characteristic of leaders would be "their capacity to learn from others and from the environment - the capacity to be taught” (p.117).

\subsection{Individual development}

King \& Nicol (1999), among other authors, tie spiritual development to a predetermined set of stages of individual development common to all people. They contend that the integration of Carl Jung and Elliot Jacques' frameworks provide managers with a context for understanding the process of individual spiritual and social growth within an organizational setting. Dehler \& Welsh (1994), Waddock (1999) cite Csikszentmihalyi's (1990) research on human development for describing the flow experience as associated with internalizing spirituality as a form of intrinsic motivation and as a form of emotional action critical to the creation of shared meaning, and distinguish between behavioral and cognitive change, showing that behavioral change based on unconscious (emotionally-based) thought precedes cognitive change, and retrospectively behavior is rationalized using cognitive information.

Korac-Kakabadse et al. (2002) describe the Eastern philosophy of Taoism and Confucianism in that every Chinese person is, at once, Taoist and Confucianist, and that the capacities of these value and belief systems are echoed in the spiritual leadership development movement. Butts (1999) describes Asian systems such as Buddhist, yogic, Vedantic, and Taoist psychologies that complement Western approaches by describing stages of transpersonal development and providing techniques for realizing them.

Biberman et al. (1999), Duignan \& Bhindi (1997), Frost \& Egri (1994), Lips-Wiersma (2001), Khanna \& Srinivas (2000), Moch \& Bartunek (submitted for publication), Neal (2000), Neck \& Milliman (1994), Wasylyshyn (2001) contend that all humans are sense-making entities and are looking for meaning or a calling in life. Some of these authors suggest that in order to make sense of their spirituality in context of their work life, people and organizations will socially construct a religion or doctrine to explain and guide their spiritual experience. Miller \& Miller (2002) contend that leaders develop spiritually by going through prescribed stages of development - being a servant of the Creator, being in the family of the Creator, and being in union with the Creator.

Several other authors do not equate spirituality with individual development. Gibbons (1999) proposes that to understand whether spirituality can be linked to human development, one must first determine the type of spirituality: religious, secular, or mystical. Cavanaugh et al. (2001) contend that nearly everyone is spiritual and that spirituality involves a deliberate way to cultivate and put forth the meaning a person gives that spirituality. Like Gibbons, they contend that if one's worldview is secular, so will be one's developmental path. If it is Zen Buddhist, one's developmental path would be through meditation, and if one's spirituality is based on Christian principles, then the path would be through religious faith.

The accumulation of literature to this point suggests that workplace spirituality can be correlated with individual development. One way in which this can be seen is in the work of Wilber (2000a), a philosopher and self-described Buddhist. Wilber has suggested that the major theorists and researchers in 
individual development have essentially all described the same path, although using different terms and different points of demarcation. An example would be his reference to the work of Beck \& Cowan (1996) in Spiral Dynamics. In this model, individuals progress through stages of development including archaic-instinctual; magical-animistic; power gods; mythic order; scientific achievement; the sensitive self; integrative; and, holistic.

\subsection{Measurable}

Several articles suggest that workplace spirituality is measurable, although few attempt it. Most identify several issues with measurement but still believe it is possible. A few articles claim that the phenomenon cannot be adequately captured using traditional social science measurement methods. We begin with several examples of attempts to measure workplace spirituality. Ashmos \& Duchon (2000) created a 34-question instrument with a 7-point Likert-type scale based on a review of the literature that led to the development of several dimensions of spirituality that could be broadly construed as contributing to inner life, meaningful work, and community. Bell \& Taylor (2001), in a participant observation study during two workshop retreats at a Benedictine monastery, measured the dimensions of language and values spirituality (belief, journey, unity, higher power, and personal fulfillment) that surround the workplace.

Perhaps the most comprehensive overview of measurement instruments is found in MacDonald, Kuentzel, \& Friedman (1999). They review ten different instruments purported to tap spirituality and related constructs. These range from the Expressions of Spirituality Inventory (cognitive orientation toward spirituality, experiential/phenomenological dimension, existential well being, paranormal beliefs, and religiousness) to the Psychomatrix Spirituality Inventory (awareness of higher power, spiritual activities or practices, use of healing practices, experience of physical and emotional trauma, body awareness, religious history, and current religious practices). An example of an instrument without reference to religion is Elkins et al. (1988) who developed a measure of humanistic-phenomenological spirituality (transcendent, meaning and purpose, mission, sacredness, spiritual values, altruism, idealism, awareness, and benefits).

Researchers have also attempted to measure spirituality for purposes of comparison. Mitchell, Hastings, \& Tanyel (2001) provided a self-administered questionnaire to American and South Korean Gen-Xers and discovered that the survey validated that both the American and South Korean groups appear to be caught up in a revival of spiritual values. Senger (1970) reports on the results of an empirical study of 244 West Coast corporate managers and their association with religious values. The religious nature of this study was unusual for its time. The "religious manager" is considered to be a manager who records high scores on the "religion factor I" value scale, reflecting a conventional, organized, religious orientation" (p. 189). Negative correlations were found with "profits, making money, doing satisfying work, and becoming a whole person" (p. 183).

Several of the authors believe that spirituality cannot be measured. Cacioppe (2000b), Fornaciari \& Dean (2001), Waddock (1999) all reference Wilber's (1997, 2000b) philosophy of ephemeral inner aspects such as emotions, values, beliefs, and community. Wilber $(1997,2000 \mathrm{~b})$ points out that these are not physical things, and, as such, cannot be empirically measured, touched, tasted, or seen. Cacioppe (2000b) points out that workplace managers are skeptical about spirituality because they see no equivalent scientific method to test its validity. He notes that while science may not be able to prove that the inner dimensions exist, others can experience them and know intuitively that they are woven into the 
fabric of the universe. Levine (1994) also talks about "knowing" what he has felt in terms of his research on spiritual communication in teams and that the empirical mode of experimentation and collection of data will never validate his assertions. Waddock (1999) argues that spirituality is more difficult to measure than other social phenomena and that the "Cartesian split" that characterizes much of Western thought makes researchers reluctant to research aspects of the spirit.

Most researchers describe the tremendous care with which measurement must proceed. It is, perhaps, most accurate to say that spirituality may not be measurable, but that there are closely correlated manifestations of spirituality which can. The primary challenge, then, is one of ensuring that appropriate proxies are selected that come extremely close to revealing the phenomenon of spirituality. The articles describing survey instruments are all possibly subject to a self-fulfilling prophecy flaw. Factor analysis is the best-practice technique for determining the suitability of items for a survey instrument. Factor analysis, though, simply takes a variety of inputs and clusters them. Consequently, it is the inputs that determine the outputs, not the factoring process. If there is any bias in the nature of the initial questions, that bias will not be removed or overcome by the factoring process.

\subsection{Productive/Profitable}

Although several articles were silent on the topic, only Konz \& Ryan (1999), among the authors researched for this paper, deny the possibility of a positive relationship between spiritual development and productivity. Many of the authors contend that spiritually empowered employees are more creative, more honest, stronger, more resilient, and more compassionate human beings (Bento, 1994). Cacioppe (2000a) concludes that spirituality in the workplace is not just good for business, it is the only way leaders and organizations can succeed. Goertzen \& Barbuto (2001) note that although spirituality is not necessarily a religious state, religiosity has been found to have a positive effect on physical health, well being, and quality of life.

King \& Nicol (1999), using Jacques' stratified systems theory, suggest that people placed in roles that match their potential capability will achieve full capacity and thus fulfill their spiritual quest. Furthermore, this growth enhances the health and performance of the organization, resulting in a new level of spirituality. Neck \& Milliman (1994) claim that spirituality values and attitudes not only have a positive effect on one's personal life, but also on an individual's job performance.

Organizational leaders who are more willing to use their personal spiritual values to make business decisions and transform organizations instill values that become the standard against which all organizational activities are measured. These organizations are believed to be more profitable and perform better (Biberman \& Whitty, 1997; Biberman et al., 1999; Bierly et al., 2000; Burack, 1999; Cacioppe, 2000a; Dehler \& Welsh, 1994; Delbecq, 1999; Konz \& Ryan, 1999; Korac-Kakabadse \& Korac-Kakabadse, 1997; Korac-Kakabadse et al., 2002; Kriger \& Hanson, 1999; Mitroff \& Denton, 1999; Porth, McCall, \& Bausch, 1999; Sass, 2000; Strack et al., 2002).

There are intellectual pitfalls in the question of whether increased workplace spirituality leads to increased productivity or profitability. Some authors note that spirituality, by definition, is antimaterialist. At the same time, although increased spirituality would presumably prohibit an individual from certain forms of work, there seems to be great promise that she or he can be more effective at performing work consistent with her or his spiritual principles.

At the current state of knowledge, determining the productivity increase of an increase in spirituality is analogous to the same calculation for a variety of organizational phenomena — culture change, 
diversity awareness, leadership improvement, and so forth. All of these examples present a controversial set of measurement examples and issues. Whether an increase in spirituality results in an increase in productivity or profitability, both causal relationships have the same set of issues; and, coupled with additional issues such as the anti-materialist nature of the phenomenon, pose significant challenges in the scientific inquiry of this category and its relationship to spiritual leadership.

\subsection{Nature of the phenomenon}

Workplace spirituality researchers tend to assume that the concept is an individual one, a collective one, or assume the phenomenon has both facets. Some authors write about the subject in a way that it is not possible to extract an implicit assumption of this dimension. Researchers who assume the phenomenon is an individual one write about it in quite different ways. For example, Tischler (1999) describes the evolution of society and organizational science, moving from an agrarian society to a postindustrial society, which focuses on the individual. Tischler uses the framework of Maslow's hierarchy of needs theory to argue that as companies and individuals become more prosperous, people can focus on higher needs, including spirituality. Bento (1994) believes that organizations have a significant influence on one's ability to express grief in the workplace. Bento describes "grief work" as emotional, psychological, and spiritual labor. The article explores the process of grieving within a workplace setting and the explicit and implicit organizational norms that influence the process.

Some researchers describe workplace spirituality as a collective phenomenon. Mitroff, Mason, \& Pearson (1994) propose a framework that acknowledges the interrelationship of the organization, its employees, its products and processes, and the world at large. Kriger \& Hanson (1999) see a collective humanity in all major spiritual and wisdom traditions. They advocate practices that facilitate the bridging of the distance between individuals in the search for collective humanity and shared truth. For many of the others who assume workplace spirituality is a collective phenomenon, the qualifier of "in organizations" is what switches the orientation from individual (outside of work) to collective (at work).

Most of the researchers describe workplace spirituality as a phenomenon with both individual and collective aspects. Bell \& Taylor (2001) note that the workplace appears to have replaced the church as a communal and supportive center for many individuals. They contend that it is therefore of great importance that the workplace be an environment where workers can bring their whole selves — both their work oriented selves and their spiritual selves. Howard (2002) notes that spirituality seems to have four sets of connections: with self, with others, with nature or the environment, and with a higher power. Mitchell et al. (2001) look at Gen X-ers and South Koreans and attribute slight differences in agreement to individual versus collective natures of the cultures.

With respect to whether the concept is an individual or collective phenomenon (or both), the vast majority of the literature suggests that there is no reason, at this point, to assume that it might not be both, and that theory development should proceed along those lines. Giacalone \& Jurkiewicz (2003) suggest both individual and collective aspects of workplace spirituality are inherent in organizations. They argue that organizational values and culture — ostensibly driven by a spiritual leader — and work processes are instrumental in achieving transcendence for individual employees. Moreover, the accumulation of evidence for Jung's collective unconscious has passed a threshold of proof for some, but not others. Similarly, the burden of proof lies with those who would see a collective spirituality. In the absence of evidence that it does not exist, a spirit of open inquiry suggests that the possibility should remain open. 


\section{Spiritual leadership theory development}

Several conclusions about theory development of workplace spirituality and leadership follow from the coding and analysis of the academic literature. Popular books are filled with the suggestion that increases in spiritual development will result in enhanced leadership effectiveness (e.g., Jones, 1996). Even in the scholarly literature, spirituality and leadership have been characterized as having "fallen in love" (Benefiel, 2003), suggesting spirituality as a new research thread in leadership theory, whereas others have suggested that the two constructs have been connected or correlated throughout history (Klenke, 2003).

For many practitioners, the surge in literature on spirituality raises the red flag that this is the next management fad especially when attempts to integrate spirituality into existing leadership and management practices are seen as simply the means through which people can be exploited (Elmes \& Smith, 2001) to improve organizational performance. Yet, given that these two constructs are being equated in contemporary social science research, findings from this study can be used to reflect upon the development of spiritual leadership theory.

\subsection{Defining workplace spirituality and leadership}

While we have discussed some of the definitions proffered by researchers in the workplace spirituality area and have selected a working definition provided by Giacalone \& Jurkiewicz (2003) as a reference point, much work still remains in crafting a definition that will satisfy most researchers who, themselves, may be writing from their own spiritual and leadership worldview. Like ice, water, and steam, workplace spirituality and spiritual leadership may be circumstantial, and emerging definitions must take that into account.

Both constructs of spirituality and leadership share the problem of not having a specific, consensus definition, and this lack of consensus in discourse perpetuates the conceptual fog and delays the progress of science (Fry \& Smith, 1987). Furthermore, combining the terms spiritual and leadership complicates the definition process in that researchers already face a bewildering array of usages of these two terms independent of one another. For example, the term spiritual may be an aspect of a person whereas leadership may be a manifestation of specific group behaviors (Drath \& Palus, 1994). Furthermore, when the concepts are combined, the newly formed unit may create definitional redundancy and lead to confounding variables in organizational and leadership research.

Among the plethora of leadership definitions, Bennis \& Nanus (1985), Cashman (1998) put forth definitions of leadership that may be a starting point for testing linkage ${ }^{1}$ with the Giacalone \& Jurkiewicz (2003) definition of workplace spirituality. Bennis \& Nanus (1985) claim that leadership is the natural expression of a fully integrated human being and Cashman (1998) describes leadership as the authentic self-expression that creates value. To date, Fry (2005) definition of spiritual leadership may provide a necessary link between the definition of leadership and workplace spirituality which can be improved upon by testing for congruence and contingency (Fry \& Smith, 1987). He defines spiritual

\footnotetext{
${ }^{1}$ Dubin (1978) model of theory building identifies four components that provide both necessary and sufficient conditions for the development of any theoretical model: units, laws of relationship, boundaries, and system states (as cited in Fry \& Smith, 1987). Laws of relationship express linkage between two or more units that can then be tested in scientific investigation; these laws of relationship portray some aspect of the real world.
} 
leadership as "the values, attitudes, and behaviors that are necessary to intrinsically motivate self and others so that they have a sense of spiritual survival (Fleischman, 1994; Maddock \& Fulton, 1998) through calling and membership" (p. 17).

\subsection{Religion}

While some authors assumed a relationship between religion and workplace spirituality, our research revealed limited scholarship linking religion with leadership. At first blush, religion may have little relationship with leadership theory. A religion, though, is essentially a belief system. Little or no research has been conducted about the spiritual or religious beliefs leaders may hold and how those beliefs may impact leader actions. Although several articles promote a distinction between spirituality and religion, many authors write as if there is no belief system that accompanies someone's spirituality. Theory development should recognize that any form of spirituality also includes practices and beliefs (i.e., a religion) and that the accompanying beliefs are an important, if not more important, element of how someone's spirituality is manifest in his or her leadership.

Interestingly, one of the most well-known leadership theories, McGregor's (1960) Theory X and Theory $\mathrm{Y}$ is about a leader's beliefs about the motivation of employees. Yet, no major research body has developed from McGregor's Theory. Some studies (e.g., Bass, 1991; Fry, 2005; Hunt, 2004; Vardi, Shirom, \& Jacobson, 1980; Yukl, 2002) describe leader belief systems in terms of values and/or attitudes and/or behaviors. Fry (2005) argues that leaders' values create their attitudes, which drive their behaviors. One can imagine, though, that there are numerous other beliefs in the religious or spiritual realms that individuals could hold that might impact their leader actions and behaviors: e.g., what do they believe about corporate social responsibility, or about loyalty, or about the importance of lifelong learning, or about a balanced work and family life, or about environmental issues, or about dozens of other possibilities? For example, research concludes that organizations must honor the whole person and the spiritual energy that is at the core of everything (Korac-Kakabadse, 2002).

Although the literature claims that [spiritual] leaders and their organizations espouse values such as love, harmony, unity, compassion, peace, truth, honesty, understanding, and tolerance in the workplace what they so often get instead is greed, cynicism, arrogance, impatience, self-doubt, envy, and moral decline (Korac-Kakabadse, 2002). What does it take to stay on a spiritual path at work or to keep others on it as well? Sandelands (2003) believes that danger lurks just on the other side of our leadership ideals. He notes that managing a business is always darker and more forbidding than we would like to believe and challenges the efficacy of teaching ethics and management principles, which the unscrupulous will abuse.

Along these same lines, Bass \& Steidlmeier (1999) warn of the dark side of charismatic/pseudotransformational leaders who purport to be authentic but instead use their positions to feed their "narcissism, authoritarianism, Machiavellianism, flawed vision, need for power. .." (p. 182). While the ethical/moral transformational leader is connected to friends, family, and community, and he or she puts their welfare ahead of his or her own, the pseudo-transformational leader may trample upon those relationships to advance his or her own agenda. Moreover, although presenting themselves as spiritual leaders, they may instead actually be false prophets. The authors argue that such pseudo-leaders take credit for others' ideas yet make others scapegoats for failure. Conversely, they contend that when transformational/spiritual leaders are morally mature, their followers consequently display higher moral reasoning. 
Similarly, Price (2003) argues that the pseudo-transformational leader embraces perverse values such as favoritism, victimization, and dependency of followers rather than empowerment. Price warns that even authentic transformational/spiritual leadership may be morally troublesome despite claims to be true to their higher selves. He fears that such leadership in and of itself can induce and maintain a leader's belief that he or she is somehow above the moral requirements that apply to the rest of the world, and he or she may rationalize engaging in prohibited behaviors whose outcome could oppress or harm innocents.

Along this line of inquiry, Ouimet's (2003) applied research and case study of the implementation and outcomes of his two-part management system (Integrated System of Management Activities-Economic and Integrated System of Management Activities-Human) found that it is possible to reconcile economic profitability with human and spiritual values. He contends that it takes at least 10 years to institutionalize such a value system and that employees must not feel pressured to participate in the spiritual aspects of the plan. By cultivating and valorizing each person's potential, the organization has withstood the normal fluctuations of the economy and human foibles. Ouimet's two-part management system provides practitioners with an innovative way to transform organizations and to develop workplace spirituality, and at the same time provides scholars with an empirical research model for studying organizations.

The Ouimet study notwithstanding, the exploration of the intersection of spiritual and religious belief systems and leadership is relatively unexplored. Giacalone, Jurkiewicz, \& Fry (in press) maintain that accentuating the split between religion and spirituality is necessary to honor the integrity of both domains.

Although there is no consensus as to whether workplace spirituality and spiritual leadership may or may not be religious in nature-researchers may want to investigate the legal implications of religion in the workplace. Researchers may want to step back from their passion about their work and evaluate whether they are promoting a cause or proselytizing their own values and beliefs, rather than advancing scientific knowledge (Giacalone \& Jurkiewicz, 2003). Promoting a cause and proselytizing may be the Achilles' heel of this research area, as indicated by the intense scrutiny and frequent criticism from those outside the interest group. Drath \& Palus (1994) note that people nearer to the center are more involved in the process of leadership (in this instance, workplace spirituality and spiritual leadership research) than are those relatively distant.

\subsection{Epiphany}

Recall that one of the categories is whether or not spiritual development occurs only in discontinuities (epiphanies). Although most of the workplace spirituality articles do not see epiphanies as the sole route to spiritual development, some do, and many others see epiphanies as common. There is limited work in this area of leadership theory. One such area is the dynamic systems study on charismatic leadership by Chanoch \& House (2001) that describes the epiphanies several charismatic leaders had that brought them into their full force of leadership.

Furthermore, a study by Bennis (2002) indicates that a leader's ability to surmount negative situations and learn from them even under the most trying circumstances often results in personal transformation. These shaping experiences may be life-threatening events or episodes of self-doubt. Bennis (2002) claims the harshest experiences expose a hidden or suppressed area of the soul and that transcending the adversity leads to spiritual development and more compassion for others. Yet, other than these examples, our review of the leadership theory literature, which was extensive but by no means comprehensive, 
does not contain a research stream that considers discontinuities in the process of leadership development. Team development research, for example, has demonstrated the utility of a punctuated equilibrium model (Gersick, 1988).

Perhaps, leadership development can also be better understood using models that include discontinuities such as cited in the Chanoch \& House (2001) study. This category had scant research from which to develop theory. While we conclude that continuous (with periodic discontinuities) should be assumed, additional research could verify this with more certainty. An organization could then plan incremental opportunities for spiritual development for both its leaders and employees. Spiritual development can be marked by epiphanies and have a continuous flow, so both of these should be included in theory development.

\subsection{Teachable}

Spiritual development in organizations can be enhanced by teaching, broadly defined. Most researchers found that workplace spirituality could be impacted by teaching. Several organizations, for example, include a spiritual development component in their leadership development activities. Just as people progress through stages of cognitive or moral development as leaders, so, too, do they progress through stages of spiritual development (Wilber, 2000a). From a practical standpoint, this should indicate that there are abundant opportunities for developing training programs and materials for organizations and, for those so inclined, facilitating training or spiritual retreats. In organizations where leaders and employees are offered formal courses believed to enhance one's spirituality or facilitate workplace spirituality, researchers should study and isolate the impact of training on organizational factors such as productivity, job satisfaction, and other variables believed to be related to the manifestation of spiritual leadership.

\subsection{Individual development}

Spiritual development appears to be a phenomenon that fits within models of overall individual development. The category of individual development opens up the possibility that leadership theorists should better explore how leadership actions and styles may be informed by the stages of human development. The very limited work in this area includes Fisher, Merron, \& Torbert (1987), who found that of the four principal developmental stages - opportunistic, social, goal-oriented, and self-defining an effective leader had to occupy one of the later developmental stages.

Fairholm (1998) has offered a developmental model with five levels of leadership perspectives. Fairholm's model integrates Graves' (1970) theory of hierarchical levels of human existence into his proposed theory of leadership, resulting in a five level virtual reality of leadership that can be ranked along a continuum from managerial control to spiritual holism (Fairholm, 1998, p. xix). Where one is on that continuum determines one's values, behaviors, actions, relationships, and measures of success. The broad outlines of this theory have been empirically validated (Fairholm, 2002). Yet, very little is known about the leadership actions of a 35-year-old CEO compared with a 60-year-old CEO. Or, how the same person leads at age 35 versus age 60. More specifically, two leaders of the same age may be in different stages of human development and lead differently. More research in this area would be of great interest and utility, particularly assessments of the relationships between human developmental stages, Fairholm's levels of leadership, and other factors of workplace spirituality, such as religiosity. 


\subsection{Measurable}

The area of measurement for workplace spirituality or spiritual leadership is ripe for additional research and development. Wilber (1998) encourages "spiritualists" to integrate their beliefs with solid scientific theories and to avoid bogus claims and narrow science. Although measurement is an exceedingly difficult task, indications at this point are that the broad brush strokes of workplace spirituality, at least, are measurable.

Certain aspects of spirituality may be so ephemeral that they cannot be measured. As an example, Fornaciari \& Dean (2001) contend that it is not possible to measure one's relationship to the sacred. Also, Newberg, D'Aquili, and Rause (2001) have used SPECT scans to measure meditative states. The process, though, requires the individual to both meditate and monitor one's own meditative state in order to alert the researcher when to perform the scan. It may be that the deepest meditative states will not allow for these dual activities and, consequently, are not measurable by any known method. However, we found various measurement instruments and surveys in our research, and contend that more are desired and necessary to lend credibility to the field. For example, can leadership behaviors and actions be measured to show that some leaders are more spiritual than others are? Can an organization as a collective be measured to be more or less spiritual than another? Most people assume that the answer to both questions is yes. However, there is little empirical research to support the argument. These are two areas of measurement that beg for validation. Additionally, organizational productivity research such as the longitudinal study by Fry, Vitucci, \& Cedillo (in press), which tests the validity and reliability of measures of the "Spiritual Leadership Theory" causal leadership model, should refine the distinction between spiritual leadership theory variables and other leadership theories and constructs.

\subsection{Productive/Profitable}

Workplace spirituality seems to offer the possibility of increasing individual effectiveness resulting in organizational performance improvement. Certainly, for many, spirituality is anti-materialist and an increase in spiritual development will result in a decreased desire for certain instrumental ends. At the same time, spiritual development appears to allow people to be more effective. If organizational goals are aligned with the areas of that enhanced effectiveness, productivity should increase. Fry et al. (in press) contend that spiritual leadership helps to create value congruence across the strategic, team and individual levels of an organization, which fosters higher levels of productivity and organizational commitment. Further studies must be conducted validating the relationship between spiritual leadership models (e.g., Fry's (2003) intrinsic motivation model of spiritual leadership) and productivity and profitability before a model of spiritual leadership can be applied broadly from an organizational development and transformation context.

\subsection{Nature of the phenomenon}

A final category with illuminating possibility is that of the nature of the phenomenon - individual or collective. Centuries of tradition and twentieth century research have made the assumption that leadership is an individual phenomenon. Only recently has the notion that leadership might be a collective phenomenon been theorized (Drath \& Palus, 1994). Drath (2001) has continued this work by suggesting that leadership should be understood not as a possession of the leader but exclusively as an 
aspect of the community (the team, group, organization, association, nation, culture). Drath (2001) frames the concept of leadership as a "communal capacity and a communal achievement" (xvi). Others discussing the emerging participative, or collective, descriptions of leadership include Bass (1991), Chanoch \& House (2001), Hunt (2004), Yukl (2002). What are the implications for organizations, then, if leadership should be regarded as a collective phenomenon?

In terms of individual or collective (organizational) workplace spirituality, Giacalone \& Jurkiewicz (2003) note that whether it is one, or the other, or an amalgamation of both is an important distinction to make. They note that such distinctions are important if studying workplace spirituality is to be distinguished from studying it in other contexts. Zinnbauer, Pargament, \& Scott (1999) argue that it should always be seen in a holistic or system context since to do otherwise would "treat it as occurring in a social vacuum" (p. 15). Although some researchers may limit their inquiry to individual spirituality, theory development, at this point should not preclude the possible existence of a collective spirituality.

In conclusion, the categories that emerged from our research as most interesting and compelling in terms of theory development and illumination of differences and distinctions offer researchers many avenues on which to travel to expand the knowledge in the field. Abundant opportunities exist for study and research, and even more exist for validating unsubstantiated claims or assumptions. The reality of today's business world is that there are decreasing economic returns because of fierce competition from those operating in a technologically driven environment. Burack (1999) argues that it will be people and people-centered leaders and organizations that will make the difference. Burack calls this concept Theory YZ (p. 280). He says that while some companies are hanging on to Theory X practice, they are thinning out. He adds that for many employees, work has become a lifestyle, and people want a good life and will go to (or stay with) organizations where they can get it. Burack defines the workplace that offers a good life as a spiritual one.

Laabs (1995) notes that "something spiritual is creeping into the workplace and it seems to be more than a trend" (p. 61). Because of the growing pervasiveness of workplace spirituality, she encourages leaders to learn about it and how it is shaping up so that they can interpret it for themselves, their employees, and the company for which they work (or, in the case of academics, for their students and for their own research). Also creeping into the workplace is recognition of the positive effects of spirituality values and attitudes. Work in positive psychology, for example, is showing that faith results in increased human health (Fry, 2005).

\section{The importance of conceptual clarity}

Finally, we return to the starting point, the definition of workplace spirituality and discovery of factors for promoting a theory of spiritual leadership. Definitions proposed in the academic literature and discussed here are not yet specific and robust enough to propel the field forward. No one has proposed a theory that specifies congruence, let alone contingency (Fry \& Smith, 1987). Theorists should take care to ensure that an appropriate definition of workplace spirituality meet criteria such as parsimony and fruitfulness (Kineman, 1997).

Of critical importance is a definition that does not overlap with other concepts such as altruism, balance, humility, or many others. As Gibbons (1999) notes, "some hard choices about what is not spiritual will have to be made. . .researchers have an obligation to draw the line somewhere and to decide which concepts are truly spiritual, and which are spiritualizing" (p. 71). If humility, for example, is part 
of being spiritual, then the concept of spirituality needs to be sited in a conceptual landscape. We are not calling for a definition which is overly reductionist or hierarchical. However, the principle of parsimony demands that a given concept perform its role while other concepts perform theirs. In a similar vein, spirituality is such a loaded term to bring in to the organizational arena that there must be compelling reasons for theorists to do so. The definition must be consistent enough so that it will not need to be modified based on individual research projects.

Our analysis and coding of the extant literature suggests that spiritual leadership theory development in this area is not far along. These articles have not provided much progress in developing "propositions" as defined by Whetten (1989) nor have there been the kind of synergistic qualitative and quantitative case study analysis as advocated by Eisenhardt (1989). Most of the articles do exhibit the tension described by Weick (1999) of shallow exploratory work that will certainly need to be modified versus more comprehensive work that cannot be completed for many years. With few exceptions, such as Mitroff \& Denton (1999), the current state of the field is clearly exploratory.

Perhaps, the most comprehensive theoretical models toward developing a theory of spiritual leadership to date are Fairholm (1998), Fry (2003). Fry's (2003) model includes intrinsic motivation as well as religious-based and ethics and values-based approaches to leadership. This model proposes conceptual distinctions among hope/faith, vision/mission, and altruistic love. The model is also causal, suggesting, for example, that hope/faith leads to vision/mission, which, in turn, leads to a calling.

Fairholm's (1998) model describes leadership as a personal reality one adopts to make sense of the dynamic interactive process of leadership. His theory suggests that the relative success of leadership is measured through the perspective of the observer and the conception of leadership held by the individual actors using a hierarchical five level behavioral-based model. Fairholm argues that we all see leadership differently depending on our current level of psychological existence, our current paradigm, our current virtual environment (Fairholm, 1998, p. xviii). The five virtual environments include: leadership as management; leadership as excellent management; values leadership; trust cultural leadership, and spiritual leadership.

The Fairholm framework suggests a more integrated and comprehensive approach to examining the contingency between individuals and task, and individuals and formal organizations (Fry \& Smith, 1987) and meets the central components of Dubin's model of theory building. Researchers of workplace spirituality should develop additional theoretical models like these and launch empirical tests of them. Yet, most models to date have been exploratory in nature. Podsakoff, MacKenzie, Podsakoff, \& Lee (2003) suggest that confirmatory analyses are to be preferred, after a very brief period of exploratory work. It could be that the field of workplace spirituality is in the transition from exploratory to confirmatory work.

The literature is filled with the promise of what the awareness of spirituality can do in an organizational context. This promise is encouraging because a definition should be "fruitful" (Kineman, 1997). However, lest this subject becomes a fad that runs its course, researchers must use the utmost care in defining this concept and showing how it is different from other concepts that can be utilized without the controversy of spirituality associated with them. Otherwise, as Bateson (1972) has noted, "Concepts that are "loosely derived and... mutually irrelevant... mix together to make a sort of conceptual fog which does much to delay the progress of science" (in Fry \& Smith, 1987, xviii).

Perhaps the research community should be asking themselves: "can we justify developing a new theory of leadership (i.e., spiritual leadership)?" Do the foundations of values-based leadership, servant leadership, and other concepts of inspired leadership provide a comprehensive treatment without adding 
new labels or a new theory of leadership to the mix? By putting forth a theory of spiritual leadership, we may be asserting that the new theory and other models of leadership, such as charismatic, transactional, and transformational leadership are mutually exclusive (Wharff, 2004). Rather, we should be calling for a more comprehensive and integrated theory of leadership that acknowledges leaders as complex beings who mature and develop over time in relationship to spiritual, emotional, cognitive, social, and physical domains and recognize that leaders have desired transcendent-related work accomplishments (Sanders et al., 2003).

In developing this integrated leadership theory, empirical results of the manifestations of leader's spiritual beliefs, activities, and practices should provide promising new ways to understand how leaders transcend and progress through the stages of human development (Wharff, 2004). Leadership and spirituality are two pervasive constructs in life and a greater understanding of how they interrelate may do much to increase the welfare of the workplace, humanity, and the environment.

\section{Acknowledgment}

The authors of this paper wish to express their deep appreciation to Jody Fry and the two anonymous reviewers of The Leadership Quarterly for their constructive and substantive comments and guidance.

\section{References}

Academy of Management. Retrieved September 26, 2004, from Management, Spirituality and Religion Web site: http:// aom.pace.edu/msr/

Ali, A., \& Gibbs, M. (1998). Foundation of business ethics in contemporary religious thought: The Ten Commandment perspective. International Journal of Social Economics, 25(10), 1152-1564.

Ashmos, D., \& Duchon, D. (2000). Spirituality at work: A conceptualization and measure. Journal of Management Inquiry, $9(2), 134-145$.

Barley, S. R., Meyer, G. W., \& Gash, D. C. (1988). Cultures of culture: Academics, practitioners and the pragmatics of normative control. Administrative Science Quarterly, 33(1), 24-60.

Bass, B. M. (1991). Stogdill's handbook of leadership: A survey of theory and research. New York: The Free Press.

Bass, B. M., \& Steidlmeier, P. (1999). Ethics, character, and authentic transformational leadership. The Leadership Quarterly, 10(2), 181-217.

Bateson, G. (1972). Steps to an ecology of mind. New York: Ballantine Books.

Beck, D. E., \& Cowan, C. C. (1996). Spiral dynamics: Mastering values, leadership, and change. Cambridge, MA: Blackwell Business.

Bell, E., \& Taylor, S. (2001). A rumor of angels: Researching spirituality and work organizations. Proceedings of the Academy of Management, MSR: A1.

Benefiel, M. (2003). Irreconcilable foes? The discourse of spirituality and the discourse of organizational science. Organization, $10(2), 383-391$.

Bennis, W. G. (2002). Crucibles of leadership. Harvard Business Review, 80(9), 39-48.

Bennis, W., \& Nanus, B. (1985). Leaders: The strategies for taking charge. New York: HarperCollins.

Bento, R. (1994). When the show must go on. Journal of Managerial Psychology, 9(6), 35-44.

Biberman, J., \& Altman, Y. (2004). Welcome to the new Journal of Management, Spirituality and Religion. Journal of Management, Spirituality and Religion, 1(1), 1-6.

Biberman, J., \& Whitty, M. (1997). A postmodern spiritual future for work. Journal of Organizational Change Management, $10(2), 130-138$.

Biberman, J., Whitty, M., \& Robbins, L. (1999). Lessons from Oz: Balance and wholeness in organizations. Journal of Organizational Change Management, 12(3), 243-252. 
Bierly III, P., Kessler, E., \& Christensen, E. (2000). Organizational learning, knowledge and wisdom. Journal of Organizational Change Management, 13(6), 595-618.

Boozer, R. (1998). Spirituality in management education. Journal of Workplace Learning, 10(6/7), 345-347.

Boyatzis, R. E. (1998). Transforming qualitative information: Thematic analysis and code development. Thousand Oaks, CA: Sage.

Brandt, E. (1996). Corporate pioneers explore spirituality peace. HR Magazine, 41(4), 82-87.

Burack, E. (1999). Spirituality in the workplace. Journal of Organizational Change Management, 12(4), $280-291$.

Burns, J. M. (1978). Leadership. New York: HarperCollins.

Butts, D. (1999). Spirituality at work: An overview. Journal of Organizational Change Management, 12 (4), 328 -331.

Cacioppe, R. (2000a). Creating spirit at work: Re-visioning organization development and leadership — Part I. Leadership and Organization Development Journal, 21(1), 48-54.

Cacioppe, R. (2000b). Creating spirit at work: Re-visioning organization development and leadership — Part II. Leadership and Organization Development Journal, 21(2), 110-119.

Cash, K., \& Gray, G. (2000). A framework for accommodating religion and spirituality in the workplace. Academy of Management Executive, 14(3), 124-134.

Cashman, K. (1998). Leadership from the inside out. Provo, Utah: Executive Excellence Publishing.

Cavanaugh, G. (1999). Spirituality for managers: Context and critique. Journal of Organizational Change Management, 12(3), $186-199$.

Cavanaugh, G., Hanson, B., Hanson, K., \& Hinojoso, J. (2001). Toward a spirituality for the contemporary organization: Implications for work, family and society. Retrieved on line 16 November 2002, Institute for Spirituality and Organizational Leadership. Proceedings from "Bridging the Gap".

Chanoch, J., \& House, R. J. (2001). Dynamics of charismatic leadership: A process theory, simulation model, and tests. The Leadership Quarterly, 12(1), 75-113.

Conger, J. A. (1994). Spirit at work. San Francisco: Jossey-Bass.

Cook-Greuter, S. (2002). A detailed description of the development of nine action logics. Retrieved January 31,2004 from. http://www.harthillusa.com/thedevelopmentofactionlogics.pdf

Csikszentmihalyi, M. (1990). Flow: The psychology of optimal experience. New York: Harper and Row.

Dehler, G., \& Welsh, M. (1994). Spirituality and organizational transformation: Implications for the new management paradigm. Journal of Managerial Psychology, 19(6), 17-26.

Delbecq, A. (1999). Christian spirituality and contemporary business leadership. Journal of Organizational Change Management, 12(4), 345-349.

Delbecq, A. (2000). Spirituality for business leadership: Reporting on a pilot course for MBAs and CEOs. Journal of Management Inquiry, 9(2), 117-128.

Dent, E. B. (2003). The interactional model: An alternative to the direct cause and effect construct for mutually causal organizational phenomena. Foundations of Science, 8(3), 295-314.

Denzin, N., \& Lincoln, Y. (2000). Handbook of qualitative research (2nd ed.). Sage Publications.

Drath, W. (2001). The deep blue sea: Rethinking the source of leadership. San Francisco: Jossey-Bass.

Drath, W. H., \& Palus, C. J. (1994). Making common sense. Greensboro: Center for Creative Leadership.

Dubin, R. (1978). Theory building. New York: Free Press.

Duignan, P., \& Bhindi, N. (1997). Authenticity in leadership: An emerging perspective. Journal of Educational Administration, 35(3), 195-209.

Eck, D. L. (2001). A new religious America. San Francisco: Harper.

Eggert, N. (1998). Contemplative leadership for entrepreneurial organizations: Paradigms, metaphors, and wicked problems. Quorum Books, Greenwood Publishing Group, Inc.

Eisenhardt, K. M. (1989). Building theories from case study research. Academy of Management Review, 14, $532-550$.

Elkins, D., Hedstrom, L., Hughes, L., Leaf, J., \& Saunders, C. (1988). Toward a humanistic-phenomenological spirituality: Definition, description, and measurement. Journal of Humanistic Psychology, 28(4), 5-18.

Elmes, M., \& Smith, C. (2001). Moved by the spirit: Contextualizing workplace empowerment in American spiritual ideals. The Journal of Applied Behavioral Science, 37(1), 33-50.

Fairholm, G. (1996). Spiritual leadership: Fulfilling whole-self needs at work. Leadership and Organization Development Journal, 17(5), 11-17. 
Fairholm, G. (1998). Perspectives on leadership: From the science of management to its spiritual heart. Westport, Connecticut: Quorum Books.

Fairholm, M. R. (2002). Conceiving leadership: Exploring five perspectives of leadership by investigating the conceptions and experiences of selected metropolitan Washington area municipal managers. Public Administration. Ann Arbor, MI: UMI.

Fisher, D., Merron, K., \& Torbert, W. R. (1987). Human development and managerial effectiveness. Group and Organization Studies, 12(3), 257-273.

Fleischman, P. R. (1994). The healing spirit: Explorations in religion and psychotherapy. Cleveland: Bonne Chance Press.

Fleiss, J. L. (1981). The measurement of interrater agreement: Statistical methods for rates and proportions. New York: John Wiley and Sons.

Fornaciari, C., \& Dean, K. (2001). Making the quantum leap: Lessons from physics on studying spirituality and religion in organizations. Journal of Organizational Change Management, 14(4), 335-351.

Fowler, J. (1981). Stages of faith: The psychology of human development and the quest for meaning. San Francisco: HarperCollins.

Freshman, B. (1999). An exploratory analysis of definitions and applications of spirituality in the workplace. Journal of Organizational Change Management, 12(4), 318-327.

Frost, P., \& Egri, C. (1994). The shamanic perspective on organizational change and development. Journal of Organizational Change Management, 7(1), 7-23.

Fry, L. W. (2003). Toward a theory of spiritual leadership. The Leadership Quarterly, 14(6), 693-728.

Fry, L. W. (2005). Toward a theory of ethical and spiritual well-being, and corporate social responsibility through spiritual leadership. In R. A. Giacalone, C. Dunn, \& C. L. Jurkiewicz (Eds.), Positive psychology in business ethics and corporate responsibility (pp. 47-84). Greenwich, CT: Information Age Publishing.

Fry, L. W., \& Smith, D. A. (1987). Congruence, contingency, and theory building. Academy of Management Review, 12(1), $117-132$.

Fry, L.W., Vitucci, S., \& Cedillo, M. (in press). Transforming the army through spiritual leadership: Theory, measurement, and establishing a baseline. The Leadership Quarterly Special Issue on Spiritual Leadership.

Gersick, C. J. G. (1988). Time and transition in work teams: Toward a new model of group development. Academy of Management Journal, 31(1), 9-41.

Giacalone, R. A., \& Jurkiewicz, C. L. (2003). Handbook of workplace spirituality and organizational performance. Armonk, NY: M.E. Sharpe.

Giacalone, R.A., Jurkiewicz, C.L., \& Fry, L.W. (in press). From advocacy to science: The next steps in workplace spirituality research. In R. Paloutzian (Ed.), Handbook of psychology and religion. Sage, Newbury Park, CA.

Gibbons, P. (1999). Spirituality at work: A pre-theoretical overview. Unpublished dissertation, Birkbeck College, University of London.

Gibbons, P. (2000). Spirituality at work: Definitions, measures, assumptions, and validity claims. Proceedings of the Academy of Management, USA, 2000.

Goertzen, B.J., Barbuto, J.E. (2001). Individual spirituality: A review of the literature. Submitted to Human Relations. Paper presented at annual Institute for Behavioral and Applied Management.

Graves, C. (1970, October). Levels of existence: An open systems theory of values. Journal of Humanistic Psychology, 10(2), $131-154$.

Harvey, J. B. (2001). Reflections on books by authors who apparently are terrified about really exploring spirituality and leadership. The Leadership Quarterly, 12(3), 377-378.

Hicks, D. (2002). Spiritual and religious diversity in the workplace: Implications for leadership. The Leadership Quarterly, 13(4), 379-396.

Howard, S. (2002). A spiritual perspective on learning in the workplace. Journal of Management Psychology, 17(3), $230-242$.

Huberman, A. M., \& Miles, M. B. (2002). The qualitative researcher's companion (2nd ed.). Sage Publications, Inc.

Hunt, J. G. (1999). Transformational/charismatic leadership's transformation of the field: An historical essay. The Leadership Quarterly, 10(2), 129-144.

Hunt, J. G. (2004). What is leadership? In J. Antonakis, A. T. Cianciolo, \& R. J. Sternberg (Eds.), The nature of leadership. Thousand Oaks, CA: Sage Publications, Inc.

Jones, L. B. (1996). Jesus CEO: Using ancient wisdom for visionary leadership. New York: Hyperion.

Kegan, R. (1982). The evolving self. Cambridge, MA: Harvard University Press. 
Khanna, H., \& Srinivas, E. (2000). Spirituality and leadership development. Presented to the roundtable conference on developing leaders, teams, and organizations: Meeting the challenges of global markets and technology, Management Development Institute, Guragon.

Kineman, J. J. (1997). Toward a special and general theory of autevolution. Boulder: Bear Mountain Institute. Retrieved April 11, 2003 from http://www.nexial.org/bmi/autevol/ghw_epi2.htm

King, S., \& Nicol, D. (1999). Organizational enhancement through recognition of individual spirituality: Reflections of Jacques and Jung. Journal of Organizational Change Management, 12(3), 234-242.

Klenke, K. (2003). The "S" factor in leadership education, practice, and research. Journal of Education for Business, 79(1), 56-60.

Kohlberg, L., \& Hersh, R. (2001). Moral development: A review of theory. Theory into Practice, 16(2), $53-59$.

Kolb, D. A. (1988). Integrity, advanced professional development, and learning. In S. Srivastva (Ed.), Executive integrity: The search for high human values in organizational life. San Francisco: Jossey-Bass.

Konz, G., \& Ryan, F. (1999). Maintaining an organizational spirituality: No easy task. Journal of Organizational Change Management, 12(3), 200-210.

Korac-Kakabadse, N. (2002). Guest editorial. Journal of Managerial Psychology, 17(3), 150.

Korac-Kakabadse, A., \& Korac-Kakabadse, N. (1997). Best practice in the Australian Public Service (APS): An examination of discretionary leadership. Journal of Managerial Psychology, 12(7), 187-193.

Korac-Kakabadse, N., Kouzmin, A., \& Kakabadse, A. (2002). Spirituality and leadership praxis. Journal of Managerial Psychology, 17(3), 165-182.

Kriger, M., \& Hanson, B. (1999). A value-based paradigm for creating truly healthy organizations. Journal of Organizational Change Management, 12(4), 302-317.

Krippendorff, K. (1980). Content analysis: An introduction to its methodology. Beverly Hills: Sage Publications.

Krishnakumar, S., \& Neck, C. (2002). The "what", "why" and "how" of spirituality in the workplace. Journal of Managerial Psychology, 17(3), 153-164.

Laabs, J. L. (1995). Balancing spirituality and work. Personnel Journal, 74(9), 60-72.

Levine, L. (1994). Listening with spirit and the art of team dialogue. Journal of Change Management, 7(1), $61-73$.

Levy, R. (2000). My experience as participant in the course on spirituality for executive leadership. Journal of Management Inquiry, 9(2), 129-131.

Lichtenstein, B. (1997). Grace, magic, and miracles. Journal of Organizational Change Management, $10(5), 393$-411.

Lips-Wiersma, M. (2001). The influence of spiritual "meaning-making" on career behavior. Journal of Management Development, 21(7), 497-520.

Lund Dean, K. (2001). Systems thinking's challenge to research in spirituality and religion at work: An interview with Ian Mitroff, unpublished interview.

MacDonald, D. A., Kuentzel, J. G., \& Friedman, H. L. (1999). A survey of measures of spiritual and transpersonal constructs: Part two - Additional instruments. The Journal of Transpersonal Psychology, 31(2), 155-177.

Maddock, R. C., \& Fulton, R. L. (1998). Motivation, emotions, and leadership: The silent side of management. Westport: Quorum Books.

Maher, M. F., \& Hunt, T. K. (1993). Spirituality reconsidered. Counseling and Values, 38(1), 21 -28.

Mason, E., \& Welsh, A. (1994). Symbolism in managerial decision making. Journal of Managerial Psychology, 9(6), $27-35$.

Maxwell, T. (2003). Considering spirituality: Integral spirituality, deep science, and ecological awareness. Zygon, 38(2), $257-276$.

McGregor, D. (1960). The human side of enterprise. New York: McGraw Hill.

Miles, M. B., \& Huberman, A. M. (1984). Qualitative data analysis: A sourcebook of new methods. Beverly Hills: Sage Publications.

Miller, W., \& Miller, D. (2002). Spirituality: The emerging context for business leadership [On-line]. Available: www.globaldharma.org

Mitchell, M., Hastings, B., \& Tanyel, F. (2001). Generational comparison: Xers in the United States and Korea. International Journal of Commerce and Management, 11(3/4), 35-53.

Mitroff, I., \& Denton, E. (1999). A study of spirituality in the workplace. Sloan Management Review, 40(4), 83-92.

Mitroff, I., Mason, R., \& Pearson, C. (1994). Radical surgery: What will tomorrow's organizations look like? Academy of Management Executive, 8(2), 11-20. 
Moberg, D., \& Calkins, M. (2001). Reflection in business ethics: Insights from St. Ignatius' spiritual exercises. Journal of Business Ethics, 33(3), 257-270.

Moch, M., \& Bartunek, J. (submitted for publication, August). Linking business, spirituality and religion. Manuscript submitted for publication.

Mohamed, A., Hassan, A., \& Wisnieski, J. (2001). Spirituality in the workplace: A literature review. Global Competitiveness, $9(1), 644-651$.

Neal, J. (2000). Work as service to the divine. American Behavioral Scientist, 12(8), 1316-1334.

Neal, J., \& Biberman, J. (2003). Introduction: The leading edge in research on spirituality and organizations. Journal of Organizational Change Management, 16(4), 363-366.

Neal, J., Bergmann Lichtenstein, B., \& Banner, D. (1999). Spiritual perspectives on individual, organization and societal transformation. Journal of Organizational Change Management, 12(3), 175-185.

Neck, C., \& Milliman, J. (1994). Thought self-leadership: Finding spiritual fulfillment in organizational life. Journal of Managerial Psychology, 9(6), 9-16.

Newberg, A., D'Aquili, E., \& Rause, V. (2001). Why God won't go away: Brain science and the biology of belief. New York: Ballantine Books.

Ouimet, J. R. (2003). The golden book: Reconciliation of human well-being with productivity and profits. Translated from the French by Steven R. Bigham. Montreal, Quebec, Canada: Ouimet-Cordon Bleu Inc.

Peck, M. S. (1980). The road less traveled. New York: Simon and Schuster.

Pheng, L. (1999). Towards managerial efficacy: Back to 2000-year old guiding principles. Learning Organization, 6(3), $121-131$

Podsakoff, P. M., MacKenzie, S. B., Podsakoff, N. P., \& Lee, J. Y. (2003). The mismeasure of man(agement) and its implications for leadership research. The Leadership Quarterly, 14(6), 615-656.

Porth, S., McCall, J., \& Bausch, T. (1999). Spiritual themes of the "learning organization". Journal of Organizational Change Management, 12(3), 211-220.

Pratt, M. (2000). Building an ideological fortress: The role of spirituality, encapsulation and sensemaking. Studies in Cultures, Organizations and Societies, 6(1), 35-53.

Price, T. L. (2003). The ethics of authentic transformational leadership. The Leadership Quarterly, 14(1), 67-82.

Reichers, A. E., \& Schneider, B. (1990). Climate and culture: An evolution of constructs. In B. Schneider (Ed.), Organizational climate and culture (pp. 5-39). San Francisco: Jossey-Bass.

Robbins, L. (2003a). From the academy of management's August 5, 2003, management, spirituality, and religion interest group's proposed minutes (pp. 5-39).

Robbins, S. (2003b). Organizational behavior. Upper Saddle River, NJ: Prentice Hall.

Sandelands, L. E. (2003). The argument for God from organizational studies. Journal of Management Inquiry, 12(2), $168-177$.

Sanders, J. E., Hopkins, W. E., \& Geroy, G. D. (2003). From transactional to transcendental: Toward an integrated theory of leadership. Journal of Leadership and Organizational Studies, 9(4), 21-31.

Sass, J. (2000). Characterizing organization spirituality: An organizational communication culture approach. Communication Studies, 51(3), 195-217.

Senger, J. (1970). The religious manager. Academy of Management Journal, 20(5/6), 179-186.

Shafranske, E. P., \& Malony, H. N. (1985, February). Religion, spirituality, and psychotherapy: A study of California psychologists. Paper presented at the meeting of the California State Psychological Association, San Francisco.

Schein, E. H. (1992). Organizational culture and leadership (2nd ed). San Francisco: Jossey-Bass.

Shrout, P. E., \& Fleiss, J. L. (1979). Intraclass correlations: Uses in assessing rater reliability. Psychological Bulletin, 86, 420-428.

Sperry, L. (1997). Leadership dynamics: Character and character structure in executives. Consulting Psychology Journal: Practice and Research, 49(4), 268-280.

Stogdill, R. M. (1974). Handbook of leadership: A survey of the literature. Journal of Psychology, 25, 35-71.

Strack, G., Fottler, M., Wheatley, M., \& Sodomka, P. (2002). Spirituality and effective leadership in healthcare: Is there a connection? Frontiers of Health Services Management, 18(4), 3-45.

Strauss, A., \& Corbin, J. (1998). Basics of qualitative research: Techniques and procedures for developing grounded theory (2nd ed.). Thousand Oaks, CA: Sage. 
Thompson, C. M. (2000). The congruent life: Following the inward path to fulfilling work and inspired leadership. San Francisco: Jossey-Bass Inc.

Tischler, L. (1999). The growing interest in spirituality in business: A long term socio-economic explanation. Journal of Organizational Change Management, 12(4), 273-280.

Tischler, L., Biberman, J., \& McKeage, R. (2002). Linking emotional intelligence, spirituality and workplace performance. Journal of Managerial Psychology, 17(3), 203-218.

Tosey, P., \& Robinson, G. (2002). When change is no longer enough: What do we mean by "transformation" in organizational change work? The TQM Magazine, 14(2), 100-109.

Vaill, P. B. (1996). Learning as a way of being: Strategies for survival in a world of permanent white water. San Francisco: Jossey-Bass.

Vardi, Y., Shirom, A., \& Jacobson, D. (1980). A study on the leadership beliefs of Israeli managers. Academy of Management Journal, 23(2), 367-382.

Waddock, S. (1999). Linking community and spirit: A commentary and some propositions. Journal of Organizational Change Management, 12(4), 332-345.

Wasylyshyn, K. (2001). On the full actualization of psychology in business. Consulting Psychology Journal: Practice and Research, 53(1), 10-22.

Weick, K. E. (1999). Theory construction as disciplined reflexivity-trade-offs in the 90s. Academy of Management Review, 24(4), 797-806.

Wharff, D.M. (2004). Expressions of spiritually inspired leadership in the public sector: Calling for a new paradigm in developing leaders. Dissertation Abstracts International, DAI-A 65(09), 3470. (UMI No. AAT 3143710).

Whetten, D. A. (1989). What constitutes a theoretical contribution? Academy of Management Review, 14, 490-495.

Wilber, K. (1997). Eye of the spirit: An integral vision for a world gone slightly mad. Boston: Shambhala.

Wilber, K. (1998). The marriage of sense and soul: Integrating science and religion. New York: Broadway Books.

Wilber, K. (2000a). A theory of everything: An integral vision for business, politics, science, and spirituality. Boston: Shambhala.

Wilber, K. (2000b). A brief history of everything (2nd ed.). Boston: Shambhala.

Yukl, G. A. (2002). Leadership in organizations (5th ed.). Upper Saddle River, NJ: Prentice Hall.

Zinnbauer, B. J., Pargament, K. I., \& Scott, A. B. (1999). The emerging meanings of religiousness and spirituality: Problems and Prospects. Journal of Personality, 67, 889-919. 